\title{
Schemes of arrangement as corporate rescue mechanisms: the Malaysia experience
}

\begin{abstract}
The objective of the schemes of arrangement (SOA) is to arrive at a binding compromise or arrangement if it is approved by the Court on all the creditors or class of creditors or on the members or class of members and also on the company or, in the case of a company in the course of being wound up, on the liquidator and contributories of the company. There are a variety of modes and forms of compromises or arrangement or both under SOA, which can be used to rescue a company or its business, which is facing financial difficulties. Furthermore, the SOA enable a company to make an application to the court for a restraining order that provides a sort of moratorium from creditors' action, giving the ailing companies time and space to negotiate the proposed Scheme that can be tailored to their needs to be rescued. This paper examines the process and effects of SOA. It also evaluates the use of the SOA in Malaysia as corporate rescue mechanisms.
\end{abstract}

